\title{
The Metacognitive Training for obsessive-compulsive disorder: A pilot study
}

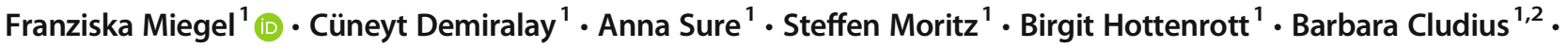 \\ Lena Jelinek ${ }^{1}$
}

Accepted: 28 October 2020 / Published online: 26 November 2020

(C) The Author(s) 2020

\begin{abstract}
More than $50 \%$ of patients with obsessive-compulsive disorder (OCD) do not receive first-line psychological treatment such as cognitive-behavioral therapy with exposure and response prevention. To narrow this treatment gap, there is an urgent need for therapies that are easy to disseminate and highly accepted by patients. The aim of the present pilot study was to evaluate the effectiveness of the Metacognitive Group Training for OCD (MCT-OCD). Fifty patients with OCD participated in the MCT-OCD for 4 weeks during their inpatient stay in a single-arm pilot trial. Patients were assessed before and after the intervention and filled out an online survey 6 months after post assessment. Results showed a decrease in obsessive compulsive symptoms according to the YaleBrown Obsessive Compulsive Scale (primary outcome) from baseline to post assessment with a large effect size. Symptom reduction remained stable over 6 months and was positively correlated with appraisal ratings of the training. The reduction in frequency of obsessive compulsive symptoms, distress due to obsessive compulsive symptoms, cognitive biases, and depressive symptoms remained stable over 6 months after the intervention. Our findings tentatively imply that the MCT-OCD is a promising treatment for OCD patients. A randomized controlled trial is thus warranted to further clarify the efficacy of the MCT-OCD. Trial Registration: German Clinical Trials Register (DRKS-ID: DRKS00012531), date of registration: 16.06.2017.
\end{abstract}

Keywords Intervention $\cdot$ Cognitions $\cdot$ Psychotherapy $\cdot$ Anxiety $\cdot$ Metacognition

\section{Introduction}

Obsessive-compulsive disorder (OCD) is a mental disorder with a lifetime prevalence of 2-3\% (Kessler et al., 2012). The disorder often has a chronic course (van Oudheusden et al., 2018), and patients with OCD frequently report a low quality of life (Moritz et al., 2005; Remmerswaal et al., 2016). The first-line psychological treatment is cognitive-behavioral therapy (CBT) with exposure and response prevention (Ex/RP; Skapinakis et al., 2016), which has shown to be effective with large effect sizes (Hedges' $g=1.31$; Öst et al., 2015). Group settings are increasingly recommended to serve the high number of patients and reduce treatment

Franziska Miegel

f.miegel@uke.de

1 Department of Psychiatry and Psychotherapy, University Medical Center Hamburg-Eppendorf, Martinistrasse 52,

20246 Hamburg, Germany

2 Department of Clinical Psychology and Psychotherapy, Ludwig-Maximilians University, Leopoldstr. 13, 80802 Munich, Germany costs (Kordon et al., 2014; Sousa et al., 2006). A recent metaanalysis (Schwartze et al., 2016) showed that group CBT for OCD was as effective as individual therapy and pharmacotherapy and superior to wait-list control (Hedges' $g=0.97,95 \%$ CI 0.58; 1.37 , $p<.001, k=4)$.

According to the guidelines of the National Institute for Health and Care Excellence (NICE, 2005), cognitive therapy (CT) is recommended either in addition to Ex/RP to enhance long-term symptom reduction or for patients who refuse to undergo Ex/RP. $\mathrm{CT}$ focuses on the identification and correction of dysfunctional interpretations of intrusive thoughts and aims to replace them with more functional ones (Pittenger, 2017). A study by Wilhelm et al. (2009) showed that CT decreased obsessive compulsive (OC) symptoms to a significantly larger extent than a wait-list control group. Two meta-analyses (Rosa-Alcázar et al., 2008; Steketee et al., 2019) showed that CT and Ex/RP were similarly effective. A more recent treatment for patients with OCD is the metacognitive therapy by Adrian Wells (Fisher \& Wells, 2008; for difference to the Metacognitive Training, see below), which 'focuses on modifying patients' beliefs about the importance of thoughts, power of thoughts and rituals using verbal reattribution and behavioral experiments" (van der Heiden et al., 2016, p. 25). 
First evidence have been demonstrated for the efficacy of this treatment (Rees \& van Koesveld, 2008; Simons et al., 2006; van der Heiden et al., 2016).

Several treatment barriers apply for OCD treatment in general (e.g., CT and metacognitive therapy) and additional treatment barriers apply for Ex/RP (Külz et al., 2010). (1) In addition to the high drop-out rates of patients when undergoing Ex/RP (14.7\%; Ong et al., 2016), $40 \%$ of therapists also avoid providing CBT with Ex/RP(Moritz et al., 2019; Voderholzer et al., 2015). As a consequence, a high number of patients are not treated with one of the first-line treatments. (2) Not many therapists specialize in treating OCD, and some even refuse to treat OCD at all (Külz et al., 2010). (3) Patients often have to wait a long time before they receive treatment, which increases the probability of a chronic course (Mataix-Cols et al., 2002). (4) Due to the low availability of therapists who are trained in CBT, CT and/or metacognitive therapy, more structured group therapies are required because they can be administered by less experienced professionals. Therefore, there is a great need for the development of lowthreshold therapies, that is, treatments that can be administered quickly even by less experienced therapists and as a result are more easily accessible for patients.

One group program that can easily be disseminated is Metacognitive Training. The first Metacognitive Training was developed for psychosis (MCT; Moritz \& Woodward, 2007) and was followed by MCTs for several disorders. The Metacognitive Trainings have shown to be effective for patients with psychosis (see latest meta-analyses by Eichner \& Berna, 2016; Liu et al., 2018), depression (Jelinek et al., 2017; Jelinek et al., 2018b) and borderline personality disorder (Schilling et al., 2018). Metacognitive Training teaches patients about disorder-specific cognitive biases (metacognitive knowledge) with the help of humorous exercises that are designed to provide corrective "aha moments" (metacognitive experiences). It is highly structured as the sessions are delivered with the help of slide-based presentations (i.e., multimedia presentation, presented with the help of a projector) and homework. The presentation mode allows therapists with less experience to conduct MCT groups. The first Metacognitive Training approach for OCD was a self-help manual (myMCT; Moritz et al., 2010), which was found to be superior to control groups (wait-list, psychoeducation) with small to medium effect sizes (Hauschildt et al., 2016; Moritz et al., 2010, 2016; for a meta-analysis see Philipp et al., 2018). Following up on recommendations of patients to combine the use of myMCT with guided (face-to-face) psychotherapy, our working group developed the MCT-OCD (Jelinek et al., 2018a). The format of this group training is very similar to that of the MCT for psychosis. The MCT-OCD addresses OCDspecific cognitive biases (e.g., perfectionism, overestimation of threat) and metacognitions because several cognitive models highlight the importance of cognitive biases (McFall
\& Wollersheim, 1979; Salkovskis, 1985; Tallis, 1995) and metacognitions in OCD (Wells, 1997, 2000). One study that investigated the role of metacognitions during treatment of OCD showed that when controlling for the overlap between predictors, changes in metacognition were significant (Solem et al., 2009). Additionally, results of a study by Grøtte et al. (2015) showed that cognitive biases (e.g., perfectionism, responsibility) were significantly correlated with OC symptoms and that a decrease in metacognitions (i.e., thought-action fusion, beliefs about rituals) predicted recovery. In its current version, the MCT-OCD has four modules that each address two cognitive biases highlighted by the Obsessive Compulsive Cognitions Working Group (OCCWG, 1997, 2001, 2003, 2005) as well as techniques developed by our working group (e.g., "association splitting"; Moritz \& Jelinek, 2011; Moritz et al., 2007; Moritz \& Russu, 2013; Jelinek et al. 2018c; see Table 1).

The contents of the MCT-OCD and CT partially overlap. Thus, the name of the intervention (MCT-OCD) reflects the proximity and the tradition in which the training was developed. This refers to the structure of the training (e.g., open group format, slide-based presentation), but also to the rationale of the intervention and the guiding motives (therapeutic attitude). In contrast to a classic CT approach (that aims to question dysfunctional assumptions by different interventions, e.g., behavioural experiments, Socratic dialogue), but in line with the other Metacognitive Trainings, MCT-OCD aims to sow doubts regarding dysfunctional beliefs. Moreover, it uses humorous elements in order to provide corrective "aha moments", which aims at raising awareness of dysfunctional mental processes (Moritz \& Lysaker, 2018), but also underlines the entertaining, interactive, playful and collaborative nature of the training.

High acceptability of MCT-OCD has already been reported for a subsample of the current data set (Jelinek et al., 2018a). The majority of patients $(90 \%)$ indicated they would recommend MCT-OCD to other patients, and they evaluated the intervention as useful and understandable. The evaluation of the module-specific effects of MCT-OCD also showed promising results (Miegel et al., 2019). The analysis of this study focused on an examination of the differential change in cognitive biases, metacognitions, and OC symptoms. Interestingly, patients' control of thoughts was the most strongly reduced after the module that targeted control of thoughts, providing the first evidence that the modules improve the targeted cognitive bias and thus are very specific.

The present study was designed to evaluate the effectiveness of the MCT-OCD in its pilot version. Besides evaluating the symptoms before and after treatment, a follow-up assessment after 6 months was carried out in order to evaluate whether the effects of the MCT-OCD were lasting (post to follow-up). We expected a symptom reduction from baseline to post as well as from baseline to follow-up assessment in the 
Table 1 Summary of each MCTOCD module (pilot version)

\begin{tabular}{ll}
\hline Module and cognitive biases & Content of the module \\
\hline $\begin{array}{l}\text { Module 1: Perfectionism/intolerance } \\
\text { of uncertainty }\end{array}$ & $\begin{array}{c}\text { This module deals with the topic of choosing standards that are too strict } \\
\text { (i.e., perfectionism) and provides exercises for setting more realistic } \\
\text { standards (e.g., being deliberately imperfect). Additionally, the } \\
\text { module conveys that there is never 100\% certainty and that patients } \\
\text { might think about which "risks" (e.g., the danger that germs could } \\
\text { still be on their skin) they might want to take again in the future. } \\
\text { This module demonstrates that persons without OCD also display forms } \\
\text { of thought-action fusion (e.g., "my team would have won if I'd } \\
\text { watched the game") in order to normalize this and other types of } \\
\text { magical thinking. Patients do thought behavioral exercises and learn } \\
\text { that not all thoughts are controllable and that suppression of thoughts } \\
\text { can paradoxically intensify these. Patients are advised to tolerate } \\
\text { these thoughts as inner noise and let them pass. } \\
\text { This module demonstrates that OCD patients tend to overestimate the } \\
\text { danger of several classes of events and suggests they consider more } \\
\text { accurate information concerning the threat and calculate the } \\
\text { probability mathematically in order to understand that their fears are } \\
\text { often very unlikely to happen. Patients also practice carefully } \\
\text { considering different sources of responsibility for certain events (i.e., } \\
\text { others, coincidence, self). } \\
\text { This module shows that OCD patients may have biased attention } \\
\text { towards OCD-relevant stimuli. Additionally, it is demonstrated that } \\
\text { cognitions are associatively linked; the technique of "association } \\
\text { splitting" (Ching and Williams, 2018; Jelinek et al., 2018c; Moritz } \\
\text { and Jelinek, 2011; Moritz et al., 2007; Moritz and Russu, 2013; } \\
\text { Rodríguez-Martín et al., 2013) is taught to help patients form new } \\
\text { positive (or neutral) associations with OCD-relevant cognitions that } \\
\text { help to reduce obsessions. }\end{array}$ \\
$\begin{array}{l}\text { Module 4: Biased attention/biased } \\
\text { cognitive networks }\end{array}$ & \\
\hline &
\end{tabular}

primary (Yale-Brown Obsessive Compulsive Scale; YBOCS) and secondary outcome parameters (Obsessive Compulsive Inventory-Revised [OCI-R], Obsessive Beliefs Questionnaire-44 [OBQ-44], Patient Health Questionnaire-9 [PHQ-9]).

\section{Methods}

\section{Design}

An uncontrolled pilot trial was conducted including patients with OCD who attended MCT-OCD sessions over a period of 4 weeks in addition to participating in a standardized inpatient treatment program (including, e.g., individual CBT, social skills training, crafts group, medication). Before the first ( $\mathrm{t} 0$; baseline assessment) and after the last MCT-OCD session (i.e., after 4 weeks, t1; post assessment), all patients participated in an assessment that included diagnostic interviews and self-rating questionnaires (see below). Six months after the post assessment, patients were invited to complete an online assessment ( 2 ; follow-up assessment). Prior to their participation, all patients had given written informed consent. The current study was approved by the Ethics Committee of the
German Psychological Society (LJ032017) and was registered with the German Clinical Trials Register (DRKS-ID: DRKS00012531).

\section{Sample}

The sample consisted of 50 patients with a primary diagnosis of OCD. Patients were recruited during their inpatient stay at the anxiety ward of the Clinic for Psychiatry and Psychotherapy of the University Medical Center HamburgEppendorf (Germany). Patients were included in the study if they were between 18 and 70 years old and did not have lifetime symptoms of psychosis (i.e., hallucinations, delusions, or mania), a severe neurological disorder, or current substance or alcohol dependence. Ward personnel (psychologists, psychiatrists, or psychiatric nurses) screened new patients for inclusion and exclusion criteria and then, if appropriate, referred them for participation in the study and scheduled an appointment with the assessor.

\section{Intervention}

Each MCT-OCD session was attended by 3 to 10 patients, was led by a psychotherapist and an assisting psychotherapist 
in training, and was administered once a week for $90 \mathrm{~min}$ (over a period of 4 weeks). Due to the open group format, patients were able to start with any module. Each module targeted two cognitive biases and followed a similar structure:

1. Short explanation of the term "metacognition"

2. Introduction of the cognitive bias

3. Explanation of the cognitive bias with the help of examples

4. Suggestion of techniques for overcoming the respective cognitive bias

5. After the session, patients received written summaries of the module and exercises to help to consolidate and deepen their knowledge and facilitate its transfer into their everyday life.

\section{Interviews and Primary Outcome Measures}

The Mini-International Neuropsychiatric Interview (M.I.N.I.; Sheehan et al., 1998), based on DSM-IV criteria, was conducted by trained raters in order to secure a diagnosis and validate inclusion as well as exclusion criteria. The primary outcome measure was the German version of the Yale-Brown Obsessive Compulsive Scale (Y-BOCS; Goodman et al., 1989a, 2089b; German version; Hand \& Büttner-Westphal, 1991), which is a semi-structured interview and is regarded as the gold standard for assessing the severity of obsessions and compulsions and was also conducted by the trained raters. The instrument is comprised of two subscales: (1) a symptom checklist to identify current as well as former experiences of OC symptoms and (2) structured questions designed to determine symptom severity.

\section{Secondary Outcome Measures}

\section{Obsessive Compulsive Inventory-Revised (OCI-R)}

The OCI-R (Foa et al., 2002; German version: Gönner et al., 2008) consists of 18 items and assesses the frequency of OC symptoms and distress experienced due to OC symptoms across 6 subscales: washing, obsessing, hoarding, ordering, checking, and neutralizing. Psychometric properties have been shown to be good for the German version (Gönner et al., 2008).

\section{Obsessive Beliefs Questionnaire-44 (OBQ-44)}

The OBQ-44 is a self-report questionnaire that consists of 44 items and taps into six typical cognitive biases in OCD (see introduction for a detailed description; OCCWG, 1997, 2001). The scale has been shown to have good convergent and discriminant validity (OCCWG, 2005) as well as good internal consistency (OCCWG, 2001, 2005).

\section{Patient Health Questionnaire (PHQ-9)}

The PHQ-9 is a self-report instrument that assesses depressive symptoms (Kroenke et al., 2001; German version: Löwe et al., 2004). Its items correspond to the DSM-IV criteria for depression and were rated on a 4-point Likert scale $(0=$ not at all, $1=$ several days, $2=$ more than half the days, and $3=$ nearly every day) allowing a range of scores from 0 to 27 . Sensitivity of the scale is good $(0.80)$, and specificity has been shown to be excellent (0.92; Gilbody et al., 2007).

\section{Subjective Appraisal of the MCT-OCD}

Patients evaluated the MCT-OCD at post and follow-up assessments. They evaluated the training by rating 18 different statements on a 5 -point Likert scale $(1=$ totally agree to $5=$ totally disagree). Two additional questions asked patients to state what they liked or disliked about the training in an open response format. For a detailed description of all items as well as patients' appraisal of the training, see Jelinek and colleagues (2018a).

\section{Strategy of Data Analysis}

SPSS 25.0 software was used to analyse the data for all participants (intention-to-treat sample, ITT) as well as the complete cases sample (CC). Missing values were imputed for main psychopathological measures by expectationmaximization (EM) algorithm, values that fall between the minimum and maximum possible values. Changes over the time of assessment (baseline, post, follow-up) were calculated using a one-way repeated measure ANOVA as well as $t$-tests (dependent sample). Effect sizes for the ANOVA were calculated by $\eta^{2}$ partial (small effect: $\eta_{\text {partial }}^{2} \approx 0.01$, medium effect: $\eta_{\text {partial }}^{2} \approx 0.06$ and large effect: $\eta_{\text {partial }}^{2} \approx 0.14$ ) and for the $t$-tests by Cohen's $d$ (small effect: $d=0.2$, medium effect: $d=0.5$, and large effect: $d=0.8$; Cohen, 1988).

\section{Results}

Table 2 presents the demographic characteristics of the ITT sample at baseline assessment $(N=50)$. Based on the M.I.N.I., 30 patients fulfilled the criteria for a current comorbid affective disorder (major depression or dysthymia), 6 for panic disorder with agoraphobia, 11 for social phobia, and 14 for generalized anxiety disorder. The number of inpatient stays ranged from 1 to 11 - Of all patients, 54\% reported one inpatient stay (the current stay), $18 \%$ reported two stays, and $12 \%$ reported four inpatient stays. At follow-up, $22 \%$ were not receiving outpatient treatment and $52 \%$ were. Patients attended on average $3.56(S D=0.76)$ MCT-OCD sessions. 
Table 2 Demographic data: mean $(S D)$ or frequency (\%)

\begin{tabular}{llc}
\hline & \multicolumn{2}{l}{ Total $(N=50)$} \\
\cline { 2 - 3 } & $M$ or $n$ & $S D$ or $\%$ \\
\hline Age (years) & 33.12 & 11.27 \\
Sex (m/f) & $24 / 26$ & $48.0 / 52.0$ \\
Years of formal education & 11.38 & 1.56 \\
Illness duration (years) & 11.70 & 11.19 \\
Age at OCD onset & 21.43 & 11.05 \\
Hospitalizations (including current) & 2.24 & 2.24 \\
Medication & & \\
Antidepressant & 19 & 38.0 \\
Antipsychotic & 3 & 6.0 \\
Combination & 13 & 26.0 \\
Benzodiazepine & 1 & 2.0 \\
Pregabalin & 1 & 2.0 \\
None & 13 & 26.0 \\
\hline
\end{tabular}

\section{Completion Rate}

Completion at post and follow-up assessments was high $(n=$ 45 post assessment, 90\%; $n=37$ follow-up, $74 \%$ ). See Fig. 1 for the participant flow.

\section{Outcome Analyses}

Table 3 displays all psychopathological data of the ITT sample for all outcome parameters at baseline, post, and follow-up assessments by $t$ - and $F$-statistics and effect sizes. The sample showed a reduction in all outcome parameters. Subsequent $t$ tests for dependent samples showed a significant reduction in the primary outcome (Y-BOCS) as well as the secondary outcome parameters (OCI-R, PHQ-9, and OBQ-44) from baseline to post as well as from baseline to follow-up assessment with medium to large effect sizes $(0.61 \leq d \leq 1.67$; $0.25 \leq \eta^{2}$ partial $\left.\leq 0.55\right)$. Improvements appeared to be stable at follow-up, with nonsignificant improvements $(1.30 \leq t \leq$ $1.93, .060 \leq p \leq .200$ ) from post to follow-up except for the OCI-R total score $(t(49)=3.91, p<.001)$. Results for the repeated measure one-way ANOVAs showed comparable effects $\left(0.61 \leq d \leq 1.74 ; 0.38 \leq \eta^{2}\right.$ partial $\left.\leq 0.57\right)$ for the CC sample ( $n=37$, see appendix Table 4$)$.

In order to evaluate the effects of the MCT-OCD on symptom decline more specifically, Pearsons correlations between Y-BOCS baseline-post difference score with the following items of the subjective appraisal were conducted: "My compulsions decreased due to the training" $(r=-.46, p=.002)$ and "my obsessions decreased due to the training" $(r=-.33$, $p=.032$ ). Correlations between Y-BOCSbaseline-follow-up difference score were also significant for the following items: "I apply the lessons learned in my everyday life" $(r=-.43$,

Fig. 1 Participant flow

\begin{tabular}{|l|l|}
\hline \multicolumn{2}{|c|}{ assessed at baseline, t0 } \\
\hline \multicolumn{2}{|c|}{ 4 week intervention (MCT-OCD) } \\
\hline completion rate 90\% & $\rightarrow \begin{array}{l}\text { lost to post assessment } \\
\bullet \text { early discharge }(n=5)\end{array}$ \\
\hline \multicolumn{2}{|c|}{ assessed at 4 weeks assessment, t1 (n=45) } \\
\hline completion rate 74\% & $\begin{array}{l}\text { lost to 6 months assessment } \\
\text { not reachable }(n=7) \\
\bullet \text { did not fill out assessment } \\
(n=1)\end{array}$ \\
\hline assessed at 6 months assessment, t2 $(n=37)$ \\
\hline \\
analyzed for CC (n=37) and for ITT $(n=50)$ \\
\hline
\end{tabular}




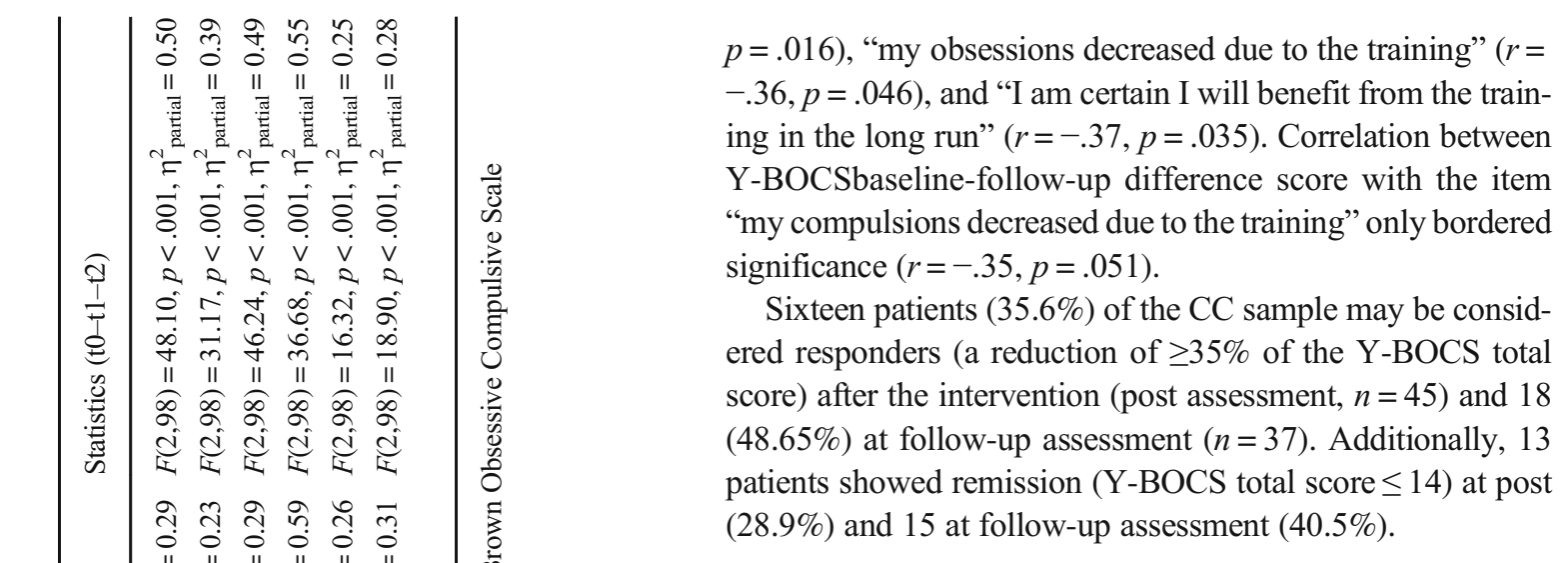

Discussion

The present study was designed to evaluate the Metacognitive Training for patients with OCD (MCT-OCD) as part of a comprehensive inpatient treatment. Patients' OC symptoms decreased significantly and with a large effect size after they participated in the MCT-OCD, and the reduction in symptoms remained stable for a period of 6 months. Depressive symptoms, cognitive biases, frequency of OC symptoms, and distress due to OC symptoms decreased after the intervention and also remained stable for a period of 6 months. More than one-third of the patients showed a clinical response (i.e., reduction of $\geq 35 \%$ in the Y-BOCS total score) after MCT-OCD, and almost $29 \%$ showed remission (Y-BOCS total score $\leq 14$ ). A current meta-analysis by Skapinakis et al. (2016) showed that patients undergoing CBT showed a symptom reduction on average of approximately 8 points on the Y-BOCS, whereas patients' symptomatology in the present study decreased by approximately 10 points. However, the results of the present study are clearly limited by the lack of control group. Thus, results only provide tentative indications that the MCT-OCD is efficacious.

The results of the present study are in line with previous research suggesting that the various elements of the MCTOCD are effective. For example, the effectiveness of association splitting has been confirmed by various studies (Ching \& Williams, 2018; Jelinek et al. 2018c; Moritz \& Jelinek, 2011; Moritz et al., 2007; Moritz \& Russu, 2013; Rodríguez-Martín et al., 2013). Furthermore, the MCT-OCD uses core elements of CT such as the normalization of thoughts (i.e., teaching patients that intrusive thoughts are not pathological per se; Marsden et al., 2018) as well as elements that are also used in the metacognitive therapy developed by Wells (especially thought-action fusion; Fisher \& Wells, 2008). Significantly, some elements of the MCT-OCD have been already examined by Moritz et al., (2010) in relation to the myMCT self-help manual, which has been evaluated positively (Hauschildt et al., 2016; Moritz et al., 2016). However, (1) the combining of these elements into one treatment, (2) the slide-supported presentation with humorous elements based on the MCT 
rationale, and (3) the presentation of these elements in a group format, which in the context of CBT-groups has proven to be extremely effective (Himle et al., 2003; Jónsson \& Hougaard, 2009; Schwartze et al., 2016) and cost-saving for patients with OCD, are all new and may exert additional effects. Importantly, the effect size in OC symptom decline in the present study from baseline to post $(d=1.48)$ is comparable to symptom decline in CBT (Hedges' $g=1.31$; see metaanalysis by Öst et al., 2015). Nevertheless, it has to be emphasized that the MCT-OCD was only administered as an add-on therapy to other effective treatment elements (e.g., CBT with Ex/RP). Thus, only conclusions regarding effectiveness for the complete treatment can be drawn. Even so, the promising results of the present study are an important first step in improving the availability of treatment for patients with OCD since the MCT-OCD can be easily disseminated because it is highly standardized and therefore easy to administer (including by less experienced therapists). Additionally, we expect that the MCT-OCD can be effective both as a stand-alone therapy and as an add-on therapy to CBT, and that it can be used to bridge waiting times. However, this assumption needs to be verified in subsequent studies with the inclusion of a control group.

Importantly, symptom reduction (from baseline to post) was associated with patients' subjective evaluation that their obsessions and compulsions were reduced due to the MCT-OCD, which mirrors their subjective satisfaction with the treatment and shows that MCT-OCD added value to the standard treatment. This provides tentative evidence that the symptom improvement is associated with the MCT-OCD and thus cannot be ascribed only to the inpatient stay and the other treatments received. Additionally, the associations between the symptom reduction from baseline to follow-up and the statement that the patients were still applying the lessons they had learned in their everyday lives and were certain they would benefit from the training in the long run have important implications because the patients apparently were still benefitting from what they had learned from the MCT-OCD 6 months after the sessions. In addition to the symptom stabilization across a period of 6 months, the aforementioned correlation provides initial evidence that the MCT-OCD might foster long-term effects. This needs to be confirmed in a randomized controlled trial of the revised MCT-OCD that is already warranted.

Important limitations need to be acknowledged. (1) The participants received inpatient treatment that included individual CBT, psychoeducation, and pharmacotherapy as well as group therapies other than the MCT-OCD. Therefore, the positive results and especially the reduction in symptoms cannot be exclusively attributed to the MCTOCD. An evaluation of the MCT-OCD in a randomized controlled study with an outpatient sample (who did not receive such intensive baseline care) would provide more accurate information about the effectiveness of the MCTOCD. Nevertheless, a study (Björgvinsson et al., 2008) that investigated the effectiveness of an intensive inpatient treatment program for patients with OCD showed significant symptom reduction with an effect size of $d=1.15$, which is a little lower than the effect size of the current study. This may support the additional effect of the MCTOCD, but this needs to be investigated further. (2) We did not include a control group, which also limits the informative value of the results. Nevertheless, a sample of inpatients, most of whom have severe symptoms, is a good way to evaluate acceptance (Jelinek et al., 2018a) and symptom progression. (3) An allegiance effect (for a meta-analysis of the allegiance effect, see Munder et al., 2012) cannot be ruled out, as the principal investigators (SM, BH, LJ) were the developers of the MCT-OCD. (4) Data for the follow-up was collected online and therefore relied on self-report only, which limits the interpretability of the follow-up data. However, because of the extensive baseline and post assessments, we decided against inviting patients for the follow-up again, which would probably have resulted in a poor completion rate. (5) The subjective appraisal questionnaire only asked for an improvement associated with the MCT-OCD but not for an improvement associated with other treatments, which may have led to an overestimation of the relevance of the MCT-OCD.

To conclude, the present study highlights the feasibility and safety of the Metacognitive Training for OCD (MCTOCD) as patients' symptoms reduced significantly and with a high effect size after their participation in the MCT-OCD and the change was correlated with their subjective appraisal ratings. Nevertheless, the pilot version of the MCT-OCD needs to be revised in order to address suggestions for improvement based on the experience of the therapists (e.g., integration of depressive cognitive biases) as well as patient feedback (e.g., less content per session; Jelinek et al., 2018a). Due to the lack of a control group the MCT-OCD needs to be evaluated more rigorously in a randomized controlled study. The intervention is a low-threshold and cost-saving treatment approach that might overcome treatment barriers for some patients who do not want to do CBT with Ex/RP. Due to its high level of standardization, the MCT-OCD can be easily applied so that a fast and easy integration into the mental care system is possible for reaching and treating a large number of patients.

Acknowledgments We would like to thank Lilian Pult for conducting the MCT-OCD groups and Lotta Zielke for support with the data collection. 
Author's Contribution FM wrote the draft of the manuscript. LJ and SM designed the study and edited the manuscript. $\mathrm{CD}, \mathrm{AS}, \mathrm{BC}$ and $\mathrm{BH}$ edited the manuscript and created the framework conditions (e.g., helping to recruit patients, providing rooms). All authors have contributed to and have approved the final manuscript.

Funding Open Access funding enabled and organized by Projekt DEAL. This research received no specific grant from any funding agency, commercial or not-for-profit sectors.

Data Availability Data and material are available from the corresponding author upon reasonable request.
Conflict of Interest MCT-OCD was developed by three of the authors (LJ, SM and BH).

Ethical Approval The current study was approved by the Ethics Committee of the German Psychological Society (LJ032017).

Consent to Participate Prior to their participation, all patients had given written informed consent.

Consent for Publication Not applicable.

Code Availability Not applicable.

\section{Compliance with Ethical Standards}

\section{Appendix}

Table 4 Psychopathological Data at Baseline-, Post-, and Follow-Up Assessments (CC sample $[n=35[$ ). Means and Standard Deviations (in Brackets) were Calculated and $t$ - as Well as $F$-Statistics and Effect Sizes (Cohen's $d$ and $\eta^{2}$ partial) Are Reported.

\begin{tabular}{|c|c|c|c|c|c|c|}
\hline Variable & Base-line (t0) & Post (t1) & Follow-up (t2) & Statistics ( $\mathrm{t} 0-\mathrm{t} 1)$ & Statistics (t0-t2) & Statistics (t0-t1-t2) \\
\hline Y-BOCS total & $25.66(5.69)$ & $17.57(6.98)$ & $16.91(7.42)$ & $\begin{aligned} t= & 8.99, p<.001, d= \\
& 1.74\end{aligned}$ & $\begin{aligned} t= & 6.65, p<.001, d= \\
& 1.32\end{aligned}$ & $\begin{array}{l}F(1,34)=44.23, p<.001, \eta_{\text {partial }}^{2}= \\
\quad 0.57\end{array}$ \\
\hline $\begin{array}{l}\text { Y-BOCS } \\
\text { obsessions }\end{array}$ & $12.97(2.80)$ & $9.31(3.73)$ & $9.00(4.44)$ & $\begin{aligned} t= & 8.97, p<.001, d= \\
& 1.90\end{aligned}$ & $\begin{aligned} t= & 5.27, p<.001, d= \\
& 1.21\end{aligned}$ & $\begin{array}{l}F(1,34)=27.81, p<.001, \eta_{\text {partial }}^{2}= \\
\quad 0.45\end{array}$ \\
\hline $\begin{array}{l}\text { Y-BOCS } \\
\text { compulsions }\end{array}$ & $12.68(3.47)$ & $8.25(3.88)$ & $7.91(3.93)$ & $\begin{aligned} t= & 6.93, p<.001, d= \\
& 1.25\end{aligned}$ & $\begin{aligned} t= & 6.59, p<.001, d= \\
& 1.19\end{aligned}$ & $\begin{array}{l}F(1,34)=43.41, p<.001, \eta_{\text {partial }}^{2}= \\
\quad 0.56\end{array}$ \\
\hline OCI-R total & $25.92(11.46)$ & $\begin{array}{l}21.55 \\
\quad(12.52)\end{array}$ & $17.45(12.87)$ & $\begin{aligned} t= & 3.38, p=.002, d= \\
& 0.81\end{aligned}$ & $\begin{aligned} t= & 5.26, p<.001, d= \\
& 0.96\end{aligned}$ & $\begin{array}{l}F(1,33)=27.04, p<.001, \eta_{\text {partial }}^{2}= \\
\quad 0.45\end{array}$ \\
\hline PHQ-9 total & $14.18(6.22)$ & $11.29(6.51)$ & $9.18(5.25)$ & $\begin{aligned} t= & 3.48, p=.001, d= \\
& 0.61\end{aligned}$ & $\begin{aligned} t= & 4.53, p<.001, d= \\
& 0.76\end{aligned}$ & $\begin{array}{l}F(1,33)=22.25, p<.001, \eta_{\text {partial }}^{2}= \\
\quad 0.40\end{array}$ \\
\hline OBQ-44 total & $\begin{array}{l}185.18 \\
(52.67)\end{array}$ & $\begin{array}{l}159.88 \\
(47.01)\end{array}$ & $148.37(58.23)$ & $\begin{aligned} t= & 4.29, p<.001, d= \\
& 0.56\end{aligned}$ & $\begin{aligned} t= & 4.29, p<.001, d= \\
& 0.78\end{aligned}$ & $\begin{array}{l}F(1,32)=19.84, p<.001, \eta_{\text {partial }}^{2}= \\
\quad 0.38\end{array}$ \\
\hline
\end{tabular}

$O B Q-44$ Obsessive Beliefs Questionnaire-44, OCI-R Obsessive Compulsive Inventory-Revised, $P H Q-9$ Patient Health Questionnaire-9, $Y$-BOCS YaleBrown Obsessive Compulsive Scale 
Open Access This article is licensed under a Creative Commons Attribution 4.0 International License, which permits use, sharing, adaptation, distribution and reproduction in any medium or format, as long as you give appropriate credit to the original author(s) and the source, provide a link to the Creative Commons licence, and indicate if changes were made. The images or other third party material in this article are included in the article's Creative Commons licence, unless indicated otherwise in a credit line to the material. If material is not included in the article's Creative Commons licence and your intended use is not permitted by statutory regulation or exceeds the permitted use, you will need to obtain permission directly from the copyright holder. To view a copy of this licence, visit http://creativecommons.org/ licenses/by/4.0/.

\section{References}

Björgvinsson, T., Wetterneck, C. T., Powell, D. M., Chasson, G. S., Webb, S. A., Hart, J., et al. (2008). Treatment outcome for adolescent obsessive-compulsive disorder in a specialized hospital setting. Journal of Psychiatric Practice, 14(3), 137-145. https://doi.org/10. 1097/01.pra.0000320112.36648.3e.

Ching, T. H. W., \& Williams, M. T. (2018). Association splitting of the sexual orientation-OCD-relevant semantic network. Cognitive Behaviour Therapy, 47(3), 229-245. https://doi.org/10.1080/ 16506073.2017.1343380.

Cohen, J. (1988). Statistical power analysis for the behavioral sciences. Hillsdale: Lawrence Earlbaum Associates. https://doi.org/10.1234/ 12345678.

Eichner, C., \& Berna, F. (2016). Acceptance and efficacy of metacognitive training (MCT) on positive symptoms and delusions in patients with schizophrenia: A meta-analysis taking into account important moderators. Schizophrenia Bulletin, 42(4), 952-962. https://doi.org/10.1093/schbul/sbv225.

Fisher, P. L., \& Wells, A. (2008). Metacognitive therapy for obsessivecompulsive disorder: A case series. Journal of Behavior Therapy and Experimental Psychiatry, 39(2), 117-132. https://doi.org/10. 1016/J.JBTEP.2006.12.001.

Foa, E. B., Huppert, J. D., Leiberg, S., Langner, R., Kichic, R., Hajcak, G., \& Salkovskis, P. M. (2002). The obsessive-compulsive inventory: Development and validation of a short version. Psychological Assessment, 14(4), 485-496. http://www.ncbi.nlm.nih.gov/pubmed/ 12501574.

Gilbody, S., Richards, D., Brealey, S., \& Hewitt, C. (2007). Screening for depression in medical settings with the patient health questionnaire (PHQ): A diagnostic meta-analysis. Journal of General Internal Medicine, 22(11), 1596-1602. https://doi.org/10.1007/s11606-0070333-y.

Gönner, S., Leonhart, R., \& Ecker, W. (2008). The obsessivecompulsiveinventory-revised (OCI-R): Validation of the German version in a sample of patients with $\mathrm{OCD}$, anxiety disorders, and depressive disorders. Journal of Anxiety Disorders, 22(4), 734-749. https://doi.org/10.1016/j.janxdis.2007.07.007.

Goodman, W. K., Price, L. H., Rasmussen, S. A., Mazure, C., Delgado, P., Heninger, G. R., \& Charney, D. S. (1989a). The Yale-Brown obsessive compulsive scale. II. Validity. Archives of General Psychiatry, 46(11), 1012-1016. http://www.ncbi.nlm.nih.gov/ pubmed/2510699.
Goodman, W. K., Price, L. H., Rasmussen, S. A., Mazure, C., Fleischmann, R. L., Hill, C. L., Heninger, G. R., \& Charney, D. S. (1989b). The Yale-Brown obsessive compulsive scale. I. Development, use, and reliability. Archives of General Psychiatry, 46(11), 1006-1011. http://www.ncbi.nlm.nih.gov/pubmed/ 2684084.

Grøtte, T., Solem, S., Vogel, P. A., Güzey, I. C., Hansen, B., \& Myers, S. G. (2015). Metacognition, responsibility, and perfectionism in obsessive-compulsive disorder. Cognitive Therapy and Research, 39(1), 41-50. https://doi.org/10.1007/s10608-014-9635-7.

Hand, I., \& Büttner-Westphal, H. (1991). Die Yale-Brown Obsessive Compulsive Scale (Y-BOCS): Ein halbstrukturiertes Interview zur Beurteilung des Schweregrades von Denk- und Handlungszwängen. Verhaltenstherapie, 1(3), 223-225. https://doi.org/10.1159/ 000257972.

Hauschildt, M., Schröder, J., \& Moritz, S. (2016). Randomizedcontrolled trial on a novel (meta-)cognitive self-help approach for obsessive-compulsive disorder ("myMCT"). Journal of ObsessiveCompulsive and Related Disorders, 10, 26-34. https://doi.org/10. 1016/J.JOCRD.2016.04.010.

van der Heiden, C., van Rossen, K., Dekker, A., Damstra, M., \& Deen, M. (2016). Metacognitive therapy for obsessive-compulsive disorder: A pilot study. Journal of Obsessive-Compulsive and Related Disorders, 9, 24-29. https://doi.org/10.1016/J.JOCRD.2016.02. 002.

Himle, J. A., Van Etten, M., \& Fischer, D. J. (2003). Group cognitive behavioral therapy for obsessive-compulsive disorder: A review. Brief Treatment and Crisis Intervention, 3(2), 217-230. https://doi. org/10.1093/brief-treatment/mhg016.

Jelinek, L., Faissner, M., Moritz, S., \& Kriston, L. (2018b). Long-term efficacy of metacognitive training for depression (D-MCT): A randomized controlled trial. British Journal of Clinical Psychology, 58(3), bjc.12213. https://doi.org/10.1111/bjc.12213.

Jelinek, L., Hauschildt, M., Hottenrott, B., Kellner, M., \& Moritz, S. (2018c). "Association splitting" versus cognitive remediation in obsessive-compulsive disorder: A randomized controlled trial. Journal of Anxiety Disorders, 56, 17-25. https://doi.org/10.1016/J. JANXDIS.2018.03.012.

Jelinek, L., Moritz, S., \& Hauschildt, M. (2017). Patients' perspectives on treatment with metacognitive training for depression (D-MCT): Results on acceptability. Journal of Affective Disorders, 221, 1724. https://doi.org/10.1016/j.jad.2017.06.003.

Jelinek, L., Zielke, L., Hottenrott, B., Miegel, F., Cludius, B., Sure, A., \& Demiralay, C. (2018a). Patients' perspectives on treatment with metacognitive training for OCD: Feasibility and acceptability. Zeitschrift für Neuropsychologie, 29(1), 20-28. https://doi.org/10. 1024/1016-264X/a000211.

Jónsson, H., \& Hougaard, E. (2009). Group cognitive behavioural therapy for obsessive-compulsive disorder: A systematic review and meta-analysis. Acta Psychiatrica Scandinavica, 119(2), 98-106. https://doi.org/10.1111/j.1600-0447.2008.01270.x.

Kessler, R. C., Petukhova, M., Sampson, N. A., Zaslavsky, A. M., \& Wittchen, H.-U. (2012). Twelve-month and lifetime prevalence and lifetime morbid risk of anxiety and mood disorders in the United States. International Journal of Methods in Psychiatric Research, 21(3), 169-184. https://doi.org/10.1002/mpr.1359.

Kordon, A., Lotz-Rambaldi, W., Muche-Borowski, C., Zurowski, B., \& Hohagen, F. (2014). Die S3-Leitlinie zur Diagnostik und Therapie der Zwangsstörungen. PiD - Psychotherapie im Dialog, 15(02), 24 29. https://doi.org/10.1055/s-0034-1376927.

Kroenke, K., Spitzer, R. L., \& Williams, J. B. W. (2001). The PHQ-9. Journal of General Internal Medicine, 16(9), 606-613. https://doi. org/10.1046/j.1525-1497.2001.016009606.x.

Külz, A., Hassenpflug, K., Riemann, D., Linster, H., Dornberg, M., \& Voderholzer, U. (2010). Ambulante psychotherapeutische Versorgung bei Zwangserkrankungen. PPmP - Psychotherapie 
Psychosomatik Medizinische Psychologie, 60(06), 194-201. https:// doi.org/10.1055/s-0029-1202837.

Liu, Y.-C., Tang, C.-C., Hung, T.-T., Tsai, P.-C., \& Lin, M.-F. (2018). The efficacy of metacognitive training for delusions in patients with schizophrenia: A meta-analysis of randomized controlled trials informs evidence-based practice. Worldviews on Evidence-Based Nursing, 15(2), 130-139. https://doi.org/10.1111/wvn.12282.

Löwe, B., Spitzer, R. L., Gräfe, K., Kroenke, K., Quenter, A., Zipfel, S., Buchholz, C., Witte, S., \& Herzog, W. (2004). Comparative validity of three screening questionnaires for DSM-IV depressive disorders and physicians' diagnoses. Journal of Affective Disorders, 78(2), 131-140. https://doi.org/10.1016/S0165-0327(02)00237-9.

Marsden, Z., Teahan, A., Lovell, K., Blore, D., \& Delgadillo, J. (2018). Patients' experiences of cognitive behavioural therapy and eye movement desensitisation and reprocessing as treatments for obsessive-compulsive disorder. Counselling and Psychotherapy Research, 18(3), 251-261. https://doi.org/10.1002/capr.12159.

Mataix-Cols, D., Rauch, S. L., Baer, L., Eisen, J. L., Shera, D. M., Goodman, W. K., Rasmussen, S. A., \& Jenike, M. A. (2002). Symptom stability in adult obsessive-compulsive disorder: Data from a naturalistic two-year follow-up study. American Journal of Psychiatry, 159(2), 263-268. https://doi.org/10.1176/appi.ajp.159. 2.263 .

McFall, M. E., \& Wollersheim, J. P. (1979). Obsessive-compulsive neurosis: A cognitive-behavioral formulation and approach to treatment. Cognitive Therapy and Research, 3(4), 333-348. https://doi. org/10.1007/BF01184447.

Miegel, F., Cludius, B., Hottenrott, B., Demiralay, C., Sure, A., \& Jelinek, L. (2019). Session-specific effects of the metacognitive training for obsessive-compulsive disorder (MCT-OCD). Psychotherapy Research, 30, 1-13. https://doi.org/10.1080/ 10503307.2019.1613582.

Moritz, S., \& Jelinek, L. (2011). Further evidence for the efficacy of association splitting as a self-help technique for reducing obsessive thoughts. Depression and Anxiety, 28(7), 574-581. https://doi.org/ $10.1002 /$ da.20843

Moritz, S., \& Lysaker, P. H. (2018). Metacognition - what did James H. Flavell really say and the implications for the conceptualization and design of metacognitive interventions. Schizophrenia Research, 201, 20-26. https://doi.org/10.1016/J.SCHRES.2018.06.001.

Moritz, S., \& Russu, R. (2013). Further evidence for the efficacy of association splitting in obsessive-compulsive disorder. An internet study in a Russian-speaking sample. Journal of ObsessiveCompulsive and Related Disorders, 2(2), 91-98. https://doi.org/10. 1016/J.JOCRD.2012.12.002.

Moritz, S., \& Woodward, T. S. (2007). Metacognitive training for schizofrenia pazients (MTC): A pilot study on feasibility, treatment adherence, and subjective efficacy. German Journal of Psychiatry, 10, 69-78. https://doi.org/10.1007/s10879-005-9001-x.

Moritz, S., Rufer, M., Fricke, S., Karow, A., Morfeld, M., Jelinek, L., \& Jacobsen, D. (2005). Quality of life in obsessive-compulsive disorder before and after treatment. Comprehensive Psychiatry, 46(6), 453-459. https://doi.org/10.1016/j.comppsych.2005.04.002.

Moritz, S., Jelinek, L., Klinge, R., \& Naber, D. (2007). Fight fire with fireflies! Association splitting: A novel cognitive technique to reduce obsessive thoughts. Behavioural and Cognitive Psychotherapy, 35(05), 631-635. https://doi.org/10.1017/ S1352465807003931.

Moritz, S., Jelinek, L., Hauschildt, M., \& Naber, D. (2010). How to treat the untreated: Effectiveness of a self-help metacognitive training program (myMCT) for obsessive-compulsive disorder. Dialogues in Clinical Neuroscience, 12(2), 209-220. http://www.ncbi.nlm. nih.gov/pubmed/20623925.

Moritz, S., Stepulovs, O., Schröder, J., Hottenrott, B., Meyer, B., \& Hauschildt, M. (2016). Is the whole less than the sum of its parts? Full versus individually adapted metacognitive self-help for obsessive-compulsive disorder: A randomized controlled trial. Journal of Obsessive-Compulsive and Related Disorders, 9, 107115. https://doi.org/10.1016/J.JOCRD.2016.04.001.

Moritz, S., Külz, A., Voderholzer, U., Hillebrand, T., McKay, D., \& Jelinek, L. (2019). "Phobie à deux" and other reasons why clinicians do not apply exposure with response prevention in patients with obsessive-compulsive disorder. Cognitive Behaviour Therapy, 48(2), 162-176. https://doi.org/10.1080/16506073.2018.1494750.

Munder, T., Flückiger, C., Gerger, H., Wampold, B. E., \& Barth, J. (2012). Is the allegiance effect an epiphenomenon of true efficacy differences between treatments? A meta-analysis. Journal of Counseling Psychology, 59(4), 631-637. https://doi.org/10.1037/ a0029571.

National Instituate for Health and Care Excellence (NICE) (2005). Obsessive-compulsive disorder: Core interventions in the treatment of obsessive-compulsive disorder and body dysmorphic disorder. NICE clinical guideline 31. British Psychological Society: Chichester.

Obsessive Compulsive Cognitions Working Group. (1997). Cognitive assessment of obsessive-compulsive disorder. Behaviour Research and Therapy, 35(7), 667-681. https://doi.org/10.1016/S00057967(97)00017-X.

Obsessive Compulsive Cognitions Working Group. (2001). Development and initial validation of the obsessive beliefs questionnaire and the interpretation of intrusions inventory. Behaviour Research and Therapy, 39(8), 987-1006. https://doi.org/10.1016/ S0005-7967(00)00085-1.

Obsessive Compulsive Cognitions Working Group. (2003). Psychometric validation of the obsessive beliefs questionnaire and the interpretation of intrusions inventory: Part I. Behaviour Research and Therapy, 41(8), 863-878. http://www.ncbi.nlm.nih.gov/ pubmed/12880642. Accessed 23 May 2018.

Obsessive Compulsive Cognitions Working Group. (2005). Psychometric validation of the obsessive belief questionnaire and interpretation of intrusions inventory - Part II: Factor analyses and testing of a brief version. Behaviour Research and Therapy, 43(11), 1527-1542. https://doi.org/10.1016/J.BRAT.2004.07.010

Ong, C. W., Clyde, J. W., Bluett, E. J., Levin, M. E., \& Twohig, M. P. (2016). Dropout rates in exposure with response prevention for obsessive-compulsive disorder: What do the data really say? Journal of Anxiety Disorders, 40, 8-17. https://doi.org/10.1016/J. JANXDIS.2016.03.006.

Öst, L.-G., Havnen, A., Hansen, B., \& Kvale, G. (2015). Cognitive behavioral treatments of obsessive-compulsive disorder. A systematic review and meta-analysis of studies published 1993-2014. Clinical Psychology Review, 40, 156-169. https://doi.org/10.1016/J.CPR. 2015.06.003.

van Oudheusden, L. J. B., Eikelenboom, M., van Megen, H. J. G. M., Visser, H. A. D., Schruers, K., Hendriks, G.-J., van der Wee, N., Hoogendoorn, A. W., van Oppen, P., \& van Balkom, A. J. L. M. (2018). Chronic obsessive-compulsive disorder: Prognostic factors. Psychological Medicine, 48, 1-10. https://doi.org/10.1017/ S0033291717003701.

Philipp, R., Kriston, L., Lanio, J., Kühne, F., Härter, M., Moritz, S., \& Meister, R. (2018). Effectiveness of metacognitive interventions for mental disorders in adults - a systematic review and meta-analysis (METACOG). Clinical Psychology \& Psychotherapy, 26, cpp.2345. https://doi.org/10.1002/cpp.2345.

Pittenger, C. (2017). In C. Pittenger (Ed.), Obsessive-compulsive disorder; phenomenology, pathophysiology, and treatment (Vol. 1). New York: Oxford University Press. https://doi.org/10.1093/med/ 9780190228163.001.0001.

Rees, C. S., \& van Koesveld, K. E. (2008). An open trial of group metacognitive therapy for obsessive-compulsive disorder. Journal of Behavior Therapy and Experimental Psychiatry, 39(4), 451-458. https://doi.org/10.1016/J.JBTEP.2007.11.004. 
Remmerswaal, K. C. P., Batelaan, N. M., Smit, J. H., van Oppen, P., \& van Balkom, A. J. L. M. (2016). Quality of life and relationship satisfaction of patients with obsessive compulsive disorder. Journal of Obsessive-Compulsive and Related Disorders, 11, 5662. https://doi.org/10.1016/J.JOCRD.2016.08.005.

Rodríguez-Martín, B. C., Moritz, S., Molerio-Pérez, O., \& Gil-Pérez, P. (2013). Effectiveness of association splitting in reducing unwanted intrusive thoughts in a nonclinical sample. Behavioural and Cognitive Psychotherapy, 41(04), 433-440. https://doi.org/10. 1017/S1352465812000513.

Rosa-Alcázar, A. I., Sánchez-Meca, J., Gómez-Conesa, A., \& MarínMartínez, F. (2008). Psychological treatment of obsessivecompulsive disorder: A meta-analysis. Clinical Psychology Review, 28(8), 1310-1325. https://doi.org/10.1016/J.CPR.2008.07. 001.

Salkovskis, P. M. (1985). Obsessional-compulsive problems: A cognitive-behavioural analysis. Behaviour Research and Therapy, 23(5), 571-583. https://doi.org/10.1016/0005-7967(85)90105-6.

Schilling, L., Moritz, S., Kriston, L., Krieger, M., \& Nagel, M. (2018). Efficacy of metacognitive training for patients with borderline personality disorder: Preliminary results. Psychiatry Research, 262, 459-464. https://doi.org/10.1016/j.psychres.2017.09.024.

Schwartze, D., Barkowski, S., Burlingame, G. M., Strauss, B., \& Rosendahl, J. (2016). Efficacy of group psychotherapy for obsessive-compulsive disorder: A meta-analysis of randomized controlled trials. Journal of Obsessive-Compulsive and Related Disorders, 10, 49-61. https://doi.org/10.1016/J.JOCRD.2016.05.001.

Sheehan, D. V., Lecrubier, Y., Sheehan, K. H., Amorim, P., Janavs, J., Weiller, E., et al. (1998). The mini-international neuropsychiatric interview (M.I.N.I.): The development and validation of a structured diagnostic psychiatric interview for DSM-IV and ICD-10. The Journal of Clinical Psychiatry, 59(Suppl 20), 22-33 quiz 34-57. http://www.ncbi.nlm.nih.gov/pubmed/9881538.

Simons, M., Schneider, S., \& Herpertz-Dahlmann, B. (2006). Metacognitive therapy versus exposure and response prevention for pediatric obsessive-compulsive disorder. A case series with randomized allocation. Psychotherapy and Psychosomatics, 75(4), 257-264. https://doi.org/10.1159/000092897.

Skapinakis, P., Caldwell, D. M., Hollingworth, W., Bryden, P., Fineberg, N. A., Salkovskis, P., Welton, N. J., Baxter, H., Kessler, D., Churchill, R., \& Lewis, G. (2016). Pharmacological and psychotherapeutic interventions for management of obsessive-compulsive disorder in adults: A systematic review and network meta-analysis. The Lancet Psychiatry, 3(8), 730-739. https://doi.org/10.1016/ S2215-0366(16)30069-4.

Solem, S., Håland, Å. T., Vogel, P. A., Hansen, B., \& Wells, A. (2009). Change in metacognitions predicts outcome in obsessivecompulsive disorder patients undergoing treatment with exposure and response prevention. Behaviour Research and Therapy, 47(4), 301-307. https://doi.org/10.1016/J.BRAT.2009.01.003.

Sousa, M. B., Isolan, L. R., Oliveira, R. R., Manfro, G. G., \& Cordioli, A. V. (2006). A randomized clinical trial of cognitive-behavioral group therapy and sertraline in the treatment of obsessive-compulsive disorder. The Journal of Clinical Psychiatry, 67(7), 1133-1139. http:// www.ncbi.nlm.nih.gov/pubmed/16889458.

Steketee, G., Siev, J., Yovel, I., Lit, K., \& Wilhelm, S. (2019). Predictors and moderators of cognitive and behavioral therapy outcomes for OCD: A patient-level mega-analysis of eight sites. Behavior Therapy, 50(1), 165-176. https://doi.org/10.1016/J.BETH.2018. 04.004 .

Tallis, F. (1995). The characteristics of obsessional thinking: Difficulty demonstrating the obvious? Clinical Psychology \& Psychotherapy, 2(1), 24-39. https://doi.org/10.1002/cpp.5640020103.

Voderholzer, U., Schlegl, S., Diedrich, A., Külz, A. K., Thiel, N., Hertenstein, E., Schwartz, C., Rufer, M., Herbst, N., Nissen, C., Hillebrand, T., Osen, B., Stengler, K., Jelinek, L., \& Moritz, S. (2015). Versorgung Zwangserkrankter mit kognitiver Verhaltenstherapie als Behandlungsmethode erster Wahl. Verhaltenstherapie, 25(3), 183-190. https://doi.org/10.1159/ 000438717.

Wells, A. (1997). Cognitive therapy of anxiety disorders: A practice manual and conceptual guide. Wiley: Chichester/New York/Weinheim/Brisbane/Singapore/Toronto.

Wells, A. (2000). Emotional disorders and metacognition: Innovative cognitive therapy. Chichester: Wiley.

Wilhelm, S., Steketee, G., Fama, J. M., Buhlmann, U., Teachman, B. A., \& Golan, E. (2009). Modular cognitive therapy for obsessivecompulsive disorder: A wait-list controlled trial. Journal of Cognitive Psychotherapy, 23(4), 294-305. http://www.ncbi.nlm. nih.gov/pubmed/21072138.

Publisher's Note Springer Nature remains neutral with regard to jurisdictional claims in published maps and institutional affiliations. 